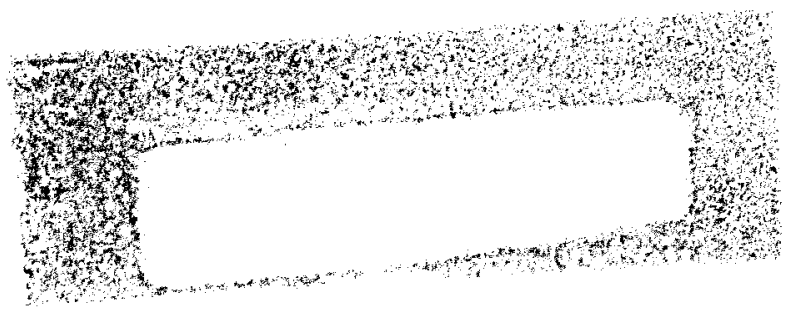

UCRL-9481

Limited dietribution

\title{
UNIVERSIT $X$ OF CALIFORNIA
}

Lawrence Radiation Laboratory

Berkeley, Callfornta

Contract No. W-7405-eng-48

\section{$*^{+}$- p Elastic scattering at 310 Movi \\ PHASE-SHIFT ANALYSIS}

James H. Foote, Owen Chamberlaln, Ernout H. Rogera, and Herbert M. Steiner

November 16, 1960 


1
1
1
1
1
1
1
1
1
1
1
1
1
1
1
1
1
1
1
1




\title{
$\pi^{+}$- p ELASTIC SCATtERING AT 310 Mov:
}

\section{PHASE-SHIFT ANALYSIS}

Jamea H. Foote, Owen Chamberlaln, Erneat H. Rogera, and Herbert M. Steiner

Lawrence Radiation Laboratory

Univeraity of Callfornia

Berkeley, Caltornta

November 16,1960

\begin{abstract}
A comprehensive phane-shift analyols of $w^{+}-p$ elastlc-ocattering data at 310-Mev incident-plon laboratory kinetic energy has been performod. The experimental data utllized Include measurements of the differential and total crow sections and of the recoll-proton polarization. The D-wave phase ablfte were found to be definitely needed in order to attain an adequate fit to the data. A general search for phaso-shift solutions was carried out, uning S-. P-, and D-wave phase ahlfte. One solution--of the Fermt type-was found that fise the data olgnificantly better than any of the other solutions obtalned. The calculated errore in the phase ahifte of thie set vary from 0.4 to 0.6 deg. Because it was felt that the are exror might be deceivingly restrictive, the effecte of emall nuclear $\mathbf{E}$-wave phase ohlfte on the result of the analyala were lnvestigated and were found to be large: not only are the uncertainties in the original Fermi-type solution increased, but addItlonal sets of phase shifts arlse that fit the data well. One of these new solution. Is aimilar to the original Ferml set except that the magnitudes of the phase ehlfta In this new fit are in general larger than those in the inftial solution, and the signs of the D-wave phase shifts are revereed. The nuclear phase ahifts in the original Ferml solution and their rma errors are (when
\end{abstract}


T-wave phace ohlfte are allowed): $S_{3,1}=-17.2 \neq 2.6$ deg, $P_{3,1}=-2.9$ \pm 4.0 deg, $P_{3,3}=135.0 \neq 0.6$ deg, $D_{3,3}=3.1 \pm 2.6$ deg, $D_{3,5}=4.9 \pm 2.1$ deg, $F_{3,5}=0.5 \neq 0.6$ deg, $F_{3,7}=-0.6 \pm 1.4$ deg. Although theory appeare to favor this set, further theoretical and experimental evidence lo doalrable. Tho values given her for the fir et flve phace ehifte approximate the correspondIng value obtained when the $I$-wave phase ehift were aceumed negliglble. However, ll except $P_{3,3}$ fall outaide the limite at by the emall orlginal errora. Inelatic-scattering processev wore noglected during the phese-ahift analyale. Calculatione Indicate that, lif these proceseos could properly be taken into account, any changes in the quoted values of the phase shifta would probably be well within the corresponding error given here. Extenulon of the phase-ohlft inquirles to Include $O$ wave wat attempted, but it was observed that the avallable data and theory do not allow the G-wave interaction to be elgnificantly incorporated into the analyale. 


\section{$\pi^{+}$- p ELASTIC SCATTERING AT $310 \mathrm{Mev}$ \\ PHASE-SHIFT ANALYSIS*}

James H. Foote. ${ }^{\dagger}$ Owen Chamberlaln, Ernest H. Rogers, and Herbert M. Steiner Lawrence Radiation Laboratory

University of Callfornia

Berkeley, Californla

November 16, 1960

\section{INTRODUCTION}

A series of axperimental measuremente on $\pi^{+}-p$ scattering at an Incldent-plon laboratory kinetic energy of 310 Mev has been completed. Data obtained include values of the recoll-proton polarization at four angles of observation, 'differential-cross-nection (DCS) meawurements at 23 distinct angles, ${ }^{2}$ and total-croes-nection values. ${ }^{2}$ The polarlzation and cross-section data are noteworthy because of the relatively high accuracy that has been attalned.

Scattering data wach as these can be analyzed in terme of phase shifts, by using the method of partial waves. The amount of muccess with which a phaso-shift analysis can be performed is a measure of the completeness of the experimental data the energy being considered. A satisfactory comprehensive theory must predict the behavior and magnitude of the phase mifts. These parameter sherefore provide a meeting place for theory and expertment. The more accurately the phase shifta are known, the more -everely 18 an acceptable theory limited.

\footnotetext{
"This work was done under the ausplces of the U. S. Atomic Energy Commission. †Present address: Lawrence Radiation Laboratory, Livermore, Callfornia.
} 
Many phase-shift analyses of $\pi^{*}-p$ cross-section data have been performed in the past. At plon laboratory kinetic energles below about 200 Mev, the experimental data have been fitted oatisfactorily by using only the firat two terms of the partial-wave expansion--that $19, S$ and $P$ waves. Above the 200-Mev energy reglon, the posatble paxticipation of $D$ waves in the plonproton Interaction has made the results of the data analyses uncertain. It has been difficult to determine the values of the $D$-wave phase ehifts because of the insensitive manner in whlch these parameter enter Into the crossnection equations and the relatively large errors In many of the crose-section measurementa. The Indefinitenes of the D-wave phase shift has introduced uncertaintiea in other phase shifts. In these earller analyses, not only have the values and algns of some of the phase shifts in a solution been uncertain, but also several different types of solution have been obtained. These dis- imilar cets of phase shift. are all good fits to the data.

We have performed a phase-shift analysis, employing the experimental data now avallable at $310 \mathrm{Mev}$. The phase-shift uncertaintles just mentioned have been Investigated. Not only has the role of $D$ waves in the $\pi^{+}-p$ Interaction been examined, but the avallable data al wo have anabled ue to extend the phase-shtft investigations to include $F$ waves.

The equations used in our analysis are discussed In Section $I 1$. The different types of phase-ahift amblgultie that have arisen in the past are brlefly mentioned there. In Section III, we describe our phase-shift inventigations, and present the results obtained. A discussion of these result followe in Section IV. ${ }^{3}$ 


\section{BASIC EQUATIONS AND RELATED DISCUSSION}

In thls section, wo prosent the equations used in our phase-shift analyats. General expresoton are given for the non-eptn-fitp and opinflp elagtic-acattering amplitudes a derived through the une of the method of partlal waver. These oquation apply to $\pi^{+}-p$ acattering and take into account both nuclear and Coulomb offects. First-order relativistic correctlone to the Coulomb-scattering amplitude will be incorporated into these equations. We include in this section the expressions, In terme of the scattering amplitudes, for the DCS and recoll-proton polarization in pionproton elastic ecattering. Finally, the variou phase-ehift ambiguitles are noted, and our notation for the phase wifts is given.

It to conventent to diwcuss the plon-proton cattering in the centerof-mass (c.m.) system. One generally lnvestigates the ocattering that take place in the horizontal plane, whlch is experimentally the ofmplest plane to treat. Conslder a right-handed $x-y-z$ Cartesian coordinate ayetem, with the pton and proton moving along the $z$ axle before the collision. Let the ocattering occur at the orlgin and allow the ty direction to be up, perpen-

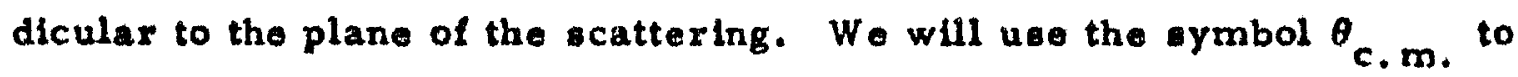
represent the angle in the c.m. system between the direction of scattering and the Intial direction of motion of elther particle. This angle will be referred to as the c.m. ecattering angle.

\section{A. Scattering Amplitudes}

The non-spin-flip and spin-flip scattering amplitude in $\pi^{+}-p$ elastic sattering can be written 


$$
\begin{aligned}
& g(\theta)=-\frac{k \eta}{2 \ln ^{2}(\theta / 2)} \exp \left\{-\ln \ln \left[\ln ^{2}(\theta / 2)\right]\right\} \\
& +\lambda \sum_{L=0}^{\infty}\left[(L+1)\left(\frac{b_{L}^{+} \exp \left(21 \delta_{L}^{+}\right)-\exp \left(21 \bar{\Phi}_{L}\right)}{21}\right)+L\left(\frac{b_{L}^{-} \exp \left(21 \delta_{L}^{-}\right)-\exp \left(21 \bar{\Phi}_{L}\right)}{21}\right) P_{L}(\cos 0)\right.
\end{aligned}
$$

and

$h(0, \phi)=\lambda \sum_{L=1}^{\infty}\left[\frac{b_{L}^{+} \exp \left(216_{L}^{+}\right)-b_{L}^{-} \exp \left(2 i 6_{L}^{-}\right)}{21}\right] D_{L} x_{L}^{ \pm 1}(\theta, \phi)$

The term "non-epln-flip" xefer to the type of ccattering In which the component of the proton opin in the direction of the incldent beam in unchanged; "apin-flip" refore to the cattering In which the component of the proton pin la reversed. In Eqa. (1) and (2), g(0) is the non-epin-flip ecattering amplitude, $h(\theta, \phi)$ is the apln-flp scattering amplitude, L to the orbital-angular-momentum quantum number, $\theta$ and $\phi$ are the pherical angular coordinates defining the direction of acattering of the particle (either pion or proton) considered to move in the ta direction before the collielon, ${ }^{4} \lambda$ is the wavolength of either particle, dividod by $2 \pi$, In the c.m. syotem, $\sigma_{L}^{\text {Le }}$ are the phase ohift describing the total (nuclear plue Coulomb) Interaction and relating to states with a poclfied $L$ and with $J L \pm 1 / 2$, where $J$ to the total-angular-momentum quantum number (these phase whift are real quantitios), b are the 'inelastic parameter." (these are real numbers with magnitudes less than or equal to unity, and take into account inelastic reactiones they are all equal to unity only If no inelastic ecattering occurs), and $P_{L}(\cos \theta)$ tw the Legendre polynomial. In addition, we have $D_{L}=[4 \pi L(L+1) /(2 L+1)]^{1 / 2}$, and

$$
\text { - } \mp\left(\frac{2 L+1)}{4 \pi L(L+1)}\right)^{1 / 2} \sin \theta \frac{d}{d(\cos \theta)}\left[P_{L}(\cos \theta)\right] \cdot 1 \phi .
$$


For $L=0$, the quantity $\Phi_{L}$ is zero; for $L \geqslant 1$,

$$
\Phi_{L}=\sum_{x=1}^{L} \tan ^{-1}(\eta / x) \text {. }
$$

with $\eta=e^{2} / \hbar v$ (positive for $\pi^{+}-p$ scattering), where $v$ is the laboratory velocity of the incident pion.

Equation. (1) and (2), In a slightly different form and with the Inolastic parameter set equal to unity, can be found in Critchfield and Dodder. 5 These equations take into account both Coulomb and nuclear scattering. Although we will refer to $\Phi_{i}$ the nonrelativistic Coulomb phase ahift of order L. It is actually the difference between the nonrelativiatic Coulomb phase shift of order $L$ and of order zero. 6 The upper aign in the expression for the epherical harmonice are to bo ueed when the proton sin is pointing in the $+z$ direction before the collision; the lower igns, when the proton apin is initially pointing in the $-\mathrm{z}$ direction.

The first term in Eq. (1) is the nonrelativistic Coulomb-8cattering amplitude, which approache infinity as the cattering angle approaches 0 deg. Becaus of this singular behavior, we will find the form of Eq. (1) advantageous. The summation in thls expression for $g(\theta)$ contains just the difference between the total and the nonrelativiatlc Coulomb-ocattering amplituden, and is expected to converge more rapidly than an expaneion in which the nonxelativiatic Coulomb-scattering amplitude has not been separated out.

The phase hift always enter into the equations in the form $2 \delta_{\mathrm{L}}^{*}$. Thu multiples of 180 deg can be added to or subtracted from the phase hlfts without changing any function of these parameters. Before quoting phasoshift values, we will frequently make changes of $180 \mathrm{deg}$ in order to reach a deaired angular region. 
Lot uo divide the phas hift describing the total interaction into a pure Coulomb part and an additional portion that arioes only when the nuclear Interaction is added to the Coulomb interaction. We then can write the total phase ohift as $\delta_{L}^{ \pm}=\Phi_{L}^{ \pm}+\delta_{L, N}^{ \pm}$. where the eymbole $\Phi_{L}^{ \pm}$ reprosent the relativistic Coulomb phase ohift of order $L$ and are ex equal to $\Phi_{L}+\Delta \Phi_{L}{ }^{\top} \cdot$ The quantitie $\Delta \Phi_{L}^{ \pm}$are correctione to $\Phi_{L}$ (the nonrelativiatic Coulomb phase ahift) due to modifications of the nonrelativiatic Coulomb scattexing. The modification that we will diecuse are the relativistic correction given by Solmitz. The quantities ${ }^{*} \mathrm{~L}, \mathrm{~N}$ approximate the plonproton nuclear phase whifte of order L. By nuclear phace ehlfte, we mean thos a that would describe the interaction if no Coulomb effect exiated. It is to be otreased that the $\sigma_{1, N}^{*}$ are only approximatione to the nuclear phase ohlftel the quantitlen obtained when the pure Coulomb phase ohifte are subtracted from the total phave ohift otll contain remnante of the Coulomb interaction. We asume that the additional correctione needed to obtain the true nuclear phase ohifte are omall. 
B. Inclusion of Flrot-Order Relativistic Coulomb Correction:

First-order relativistic corrections to the nonrelativistic Coulombacattering amplitudes can be written

$$
\Delta_{\mathbf{g}_{C}}=\lambda \eta \mathrm{A} \quad \text { (non-opin-flip correction). }
$$

and

where

$$
\Delta h_{C}=\mp \frac{\lambda \eta B \operatorname{in} \theta}{2 \sin ^{2}(\theta / 2)} e^{-i \phi}(\text { apin-nlp correction). }
$$

$$
A=\frac{\left(\beta_{\pi} \beta_{p}\right) / 2+\left(2 \mu_{p}-1\right) p^{2}{ }_{p}^{/ 4}}{1+\beta_{\pi} \beta_{P}} \text {. }
$$

and

$$
B=\frac{\left(\mu_{p}^{\beta} \beta^{\beta} \beta_{p}\right) / 2+\left(2 \mu_{p}-1\right) \beta_{p}^{2} / 4}{1+\beta_{\pi} \beta_{p}}
$$

Hex $\beta_{P}$ and $\beta_{\pi}$ are the c.m. velocities of the proton and pion, respectively, divided by the velocity of 11 ght, and $\mu_{P}$ is the magnetic moment of the proton In nuclear magnetons. The other quantities in Eqw. (5) and (6) have been previouly defined. These formulas were obtalned from Eqg. (2) and (3) of Solmitzi 8 we used the relationship $v / c=\left(\beta_{\pi}+\beta_{p}\right) /\left(1+\beta_{\pi} \beta_{p}\right)$. where (as in the expression for $\eta v$ is the laboratory velocity of the incldent plon. The effect of the magnetic moment of the proton is included in the e corrections. The double ign before the expression for ${ }^{\Delta h} C^{\prime}$ and the e ${ }^{ \pm 1}$ factor after. are necessary to account for the two possible initial opin atates. The doubleeign convention is the ame as in Eqs. (2) and (3) of thie report. The order of these igne has been chosen so that the relative phase of the nuclear and Coulomb spin-flip cattering amplitudes in Eq. (1) of reference 8 agrees with the corroponding relative phase in our Eq. (8). 
To incorporate thene corrections into our analysis, we decompose them into partial waves. Thi allows them to be separated into two parto-one corrosponding to tate with $L \leqslant L_{M A X}$ and the econd containing the remainder. The quantity $L_{M A X}$ is the maximum value of the quantum number L whose related partial wave is affected by the nuclear interaction. For $L \leqslant L_{M A X}$ unitarity is maintained by employing the usual partial-wave expression. but now interpreting part of each phase wift as ariaing from the correction termu. These phase-ahift corroction are eatimated by comparIng the firot-order Solmita corrections with Eqs. (1) and (2) taken to lowest order. Our basic aseumption is that these correction to the Coulomb phase whif are not altered by the other Interactiona. Wo subtract them, along with the nonrelativiatic Coulomb phase ohifta, from the total phase ahifto, to obtaln entimates of the nuclear phase ohifte. In contrast to the method for $L \leqslant L_{M A X}$ the part of the correction $\Delta{ }_{C}$ for $L>_{L_{M A X}}$ is oimply added to the reet of the epin-flip scattering amplitude, with no attempt to proserve unitarity in the higher-order atates. Because $\Delta_{g_{C}}$ lo independent of angle, it is entirely taken into account by the correction to the S-wave phase ahift.

The procedure just described yielde the following expressions for the corrections to the nonrelativiatic Coulomb phase ahifta

$$
\begin{aligned}
\Delta \Phi_{0}\left(=\Delta \bar{\Phi}_{0}^{+}\right) & \approx \Delta_{\mathbf{B}_{C}} M . \\
& \Delta \Phi_{L}^{+}=\frac{\eta B}{L+1} \text { for } L \geqslant 1 . \\
& \Delta \Phi_{L}^{-} \approx \frac{\eta B}{L} \text { for } L \geqslant 1 .
\end{aligned}
$$


Uaing these reaults and Eq. (4), we can compute the number presented in Table I. It is observed that the quantitie $\Delta \Phi_{\mathrm{L}}^{t}$ are omall and, for low L. $\Phi_{L}$ is also small. Thus, for low $L$ and $\theta$ not too near 0 deg, the approximatione made in expanding Eqs. (1) and (2) to firwt order (with only the Coulomb interaction allowed) are juntified.

Handling the Solmits correctiong as discussed, we can write the non-spin-flip and pin-flip elastic-scattering amplitudes a.

$$
\begin{aligned}
& g(\theta)=-\frac{h \eta}{2 \ln ^{2}(\theta / 2)}\left\{\exp -\ln \ln \left[\sin ^{2}(0 / 2)\right]\right\} \\
+\sum_{L=0}^{L} & {\left[(L+1)\left(\frac{b_{L}^{+} \exp \left(21 \delta_{L}^{+}\right)-\exp \left(2 i \Phi_{L}\right)}{21}\right)\right.} \\
& \left.+L\left(\frac{b_{L}^{-} \exp \left(216_{L}^{-}\right)-\exp \left(21 \Phi_{L}\right)}{21}\right)\right] \times P_{L}(\cos \theta) .
\end{aligned}
$$

and

$$
h(\theta, \phi)=\mp \frac{\lambda \eta \sin \theta}{2 \sin ^{2}(\theta / 2)} e^{ \pm 1 \phi}
$$

$+\lambda \sum_{L=1}^{L}\left[\frac{\left.\left.b_{L A X}{ }^{\exp \left(21 \delta^{+}\right.} L_{L}\right)-b^{-} L^{\exp \left(21 \delta^{-}\right.} L_{L}\right)}{2 t}-\eta B\left(\frac{2 L+1}{L(L+1)}\right)\right] D_{L} Y_{L}^{ \pm 1}(\theta, \phi)$

The part of the correction $\Delta_{C}$ for $L>_{L_{M A X}}$ has been included in $h\left(\theta_{0} \phi\right)$ by adding the entire $\Delta h_{C}$ and then subtracting off the $L \leqslant L_{M A X}$ portion. Wo ummarlze the olgn conventions employed in Equ. (7) and (8): 
(a) In each place where double algni occur in the expression for $h(\theta, \phi)$, the upper aign 1. to be used when the proton apln 16 pointing in the +2 drection before the collieion; the lower sign, when the proton epln is initially pointing in the - a direction.

(b) The t superecripta on $b_{L}$ and $b_{L}$ refer to etates with $J=L \pm 1 / 2$.

Equation (7) and (8) are almilar to exprestons that are obtalned if ono imply adde the nuclear and Coulomb ecattering amplitudes. However, differences exdet because the method presented here adde nuclear and Coulomb phase shlfta rather than amplitudes for $L \leqslant L$ MAX Except for the modification: due to the Solmite correctione, our approach la esentially that used by Stapp, Ypsilantia, and Metropolie. 9

C. Crose-Section and Polarization Expreselone

To obtain expreation: for the DCS and recoil-proton polariation in elavtic $\pi^{+}-p$ ecattering in terme of phase wifts, when both nuclear and Coulomb effect: are present, we use the equations

$$
I\left(\theta_{\text {c. m. }}\right)=\left|\mathrm{s}_{\mathrm{aa}}\right|^{2}+\left|\mathrm{h}_{\beta a}\right|^{2} \text {. }
$$

and

$$
P\left(\theta_{\text {c.m. }}\right)=\frac{2 \operatorname{Im}\left(g_{a a_{\beta a}^{*}}^{m} h^{\prime}\right.}{I\left(\theta_{\text {c.m. }}\right)} \text {. }
$$

Here the quantity $g_{a a}$ is given directly by Eq. (7), and $h_{\beta a}$ is given by Eq. (8) when one sets $\phi=0$ or 180 deg and employ the upper ign in each place where double signe occur. 
Equation (10) follow from the results of Fermi' article, ${ }^{10}$ and Eq. (9) can be found, in a somewhat different form, in Bethe and de Hoffmann. 11 In obtaining Eq. (10), we have used the polarization definition $P=\left(N_{U}-N_{D}\right) /\left(N_{U}+N_{D}\right)$, where $N_{U}$ and $N_{D}$ are the intensities of recoiling protons with their spin vectors polnting in the $+y$ (assumed up) and $-y$ (assumed down) directions, respectively. The oubscripts and $\beta$ denote the proton opin states in which the spin points in the $+z$ and $-x$ directions, respectively. The firet subscript on $g$ and $h$ reform to the opln atate after the colliaion, and the aecond to the epin otate befor tho colliaion (the roveroe of Fermi' ubscript notation). In obtaining Eq. (10), we have ueed $h_{\beta a}=-h_{\alpha \beta}$ a relationship that can bo seen from Eq. (8) to be valid for $\phi=0$ and 180 deg. Thi apecification of the $\phi$ value 1 actually no $x$ estriction because one may choone the $x-z$ plane, which contain. $\phi=0$ and $180 \mathrm{deg}$. to coincide with any cattering plane of interest. With $\phi$ secified, $g_{a a}$ and $h_{\beta a}$ depend only on the on angular coordinate $\theta$. Because $\theta$ can refer to the angle between the direction of sattering and the initial direction of motion of oither particle, we have used the ymbol $\theta_{\text {c.m. }}$ in Eq. (9) and (10). following the definition at the beginning of Section II. 
D. Ambiguities and Phase-Shift Notation

Owing to the nature of the equations, more than one set of phase shift have arisen in the analysi of pion-proton cattering data. Each set has distinct characterigtic and, within certain limitationa, yields a satis factory fit to the expeximental data. It lo important to determine which of the several possible solutions corresponds to the true olution. The various uncertalnties in the $\pi^{+}-p$ phase ohift may be classed an the FermiYang-Minami ambigulty. ${ }^{12-14}$ the D-wave phase-shift amblguity, ${ }^{15}$ and the uncertainty in the absolute $1 \mathrm{gn}$ of a given set of phase ohift. ${ }^{12}$ We shall let the term "Minami-Yang" refer to the aet of phase shifte obtained when the Minamt transformation 10 applled to the Yang set, ${ }^{13}$ as opposed to the "Minaml" set, which is imilarly obtained from the ferml-type oolution. The phase-ehift notation that we will employ 18 given in Table II. The conventional eymbols for the S-, P-, and D-wave phase shifts have been modified to preaent a conelstent notation when $F$ wave are included in the analysis. As before, the first ubacript io twice the total isotopic opin, and the aecond if twice the total angular momentum. Because we are dealing with $\pi^{+}$-p cattering, only the state with isotopic spin of $3 / 2$ enters into the interaction. 


\section{PHASE-SHIFT ANALYSIS}

Our phase-shift analyois and the reault obtained will now be discussed. 16 We first examine the general method used in these investigations. Then, we describe the analysis involving $S, P$, and $D$ waves and the evidence that the D-wave phase hift axe needed in ordex to attain an adequate fit to the data. The ambiguity in the $D$-wave phas shift is mentioned. Finally, the inclusion of $F$ wavea in the analyois is diocused, and also described to the attempt to add a waves.

\section{A. General Method}

In the analyaif of our experimental cross-section and polarization data. we used an IBM-704 electronic computer and the formulas presented in soction II. The grid seaxch procedure was employed, in whlch tho phase ahift are varied in cyclea. 17 When varying phase whift by the increment $\Delta$, our computer program makes use of the equality exp $[2 i(\sigma+\Delta)]=\exp (2 i \delta)$ $x \exp (21 \Delta)$. Thi equation, when eparated into roal and imaginary part., contain the aine and conine of 28 and $2 \Delta$ on the right-hand ide. After these four trigonometric functione have been initially calculated, variations of the size $\Delta$ can be made in 6 without tho computation of any new trigonometric functions. Because only relatively simple axithmetic operations are involved, this method reduces the computational time. 18

Our program is arranged o that. in the search for a fit to the data, tho computer varies the phase ohift but not the inelantic parameters. In the major portion of our phase-ohift investigations, and unless otherwse stated, the inelastic parameter were as oumed to be unity; that is, only elastic ecattering wa allowed. This assumption is reasonable owing to the apparently - mall amount of inelastic scattering at $310 \mathrm{Mev}$ (see Section IV-A). If there 
were ubstantial inelastic ocattering, the inelastic parameter could be conolderably 108 s than unity. We might then have had to vary both the inelastic parametor and the phase shifts in the search for the true oolution, and the analysio would have become more complicated.

Although we generally disregarded 1nelastlc cattering, we eventually wanted to Investigate it influence on the result of the phase-ahift analysis. Our program enable the computer to accept aelected value of the inelastlc parameter and employ these initial value throughout the search procedure. Varioue combinationa of the parameter can be chosen, the molution of interest can be redetermined, and tho rowltant phase-ohift changes can be examined. In this way, one 1o able to obtain estimates of the errors introduced into the analyalo by the assumption that all the inelatic parameter. are unity.

The predictions of a given set of phase shift axe compared with the avallable experimental data by computing the quantity $M$, where

$$
M=\sum_{1} \frac{x_{1}^{(c)}-x_{1}^{(0)}}{E_{1}^{2}}
$$

Here $x_{i}^{(e)}$ is the quantity $x_{1}$ as obtained from experiment, $E_{1}$ is the exporimental error (etandard deviation) in $x_{i}^{(e)}$, and $x_{1}^{(c)}$ to the quantity $X_{1}$ as calculated by the computer from a given wet of phase ahifto. Wo oum over all the experimental measurement.

Expressing $M$ in terms of quantities for which we have experimental datn, we write

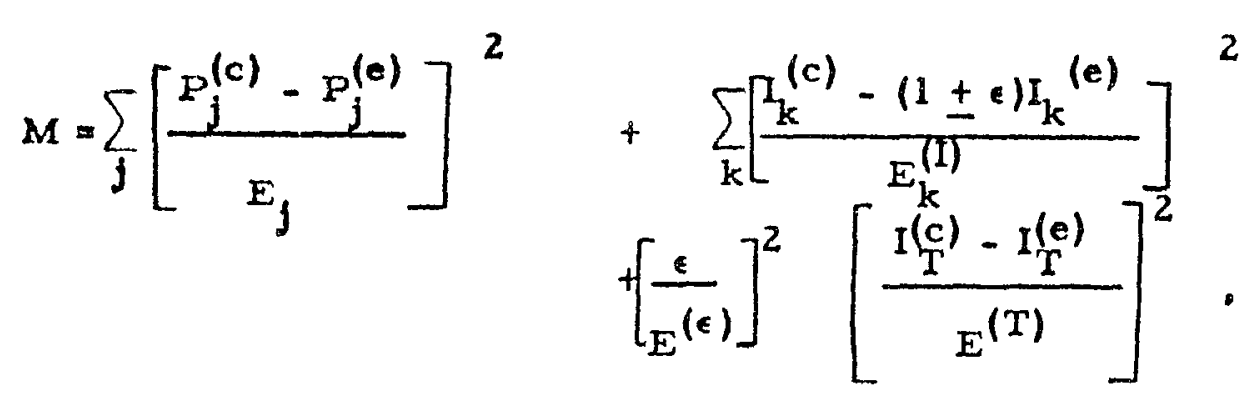


where $P_{j}$ la the polarization of the recoil protons at the c.m. scattering angle $\theta_{\mathrm{c} . \mathrm{m}}^{(j)}, E_{j}^{(P)}$ is the experimental error in $P_{j}^{(e)}, I_{k}$ is the elastic DCS for scattering at the c.m. angle $\theta_{\mathrm{c} . \mathrm{m}}^{(\mathrm{k})}, \mathrm{E}_{\mathrm{k}}^{(\mathrm{I})}$ is the experimental exror in $\mathrm{I}_{\mathrm{k}}^{(e)}$. Is the variable normalization parameter for the DCS. $E(1)$ is the experimental error in (the experimental value of $\left.1 \mathrm{~s} 0 \pm \mathrm{E}^{(0)}\right), I_{\mathrm{T}}$ is the total cross section (elastic plus inelastic) between the cutoff angles $\theta_{c . m \text {. }}^{(1)}$ and $\theta_{c . m .}^{(2)}$, and $\mathrm{E}^{(\mathrm{T})}$ is the experimental exror in $I_{T}^{(e)}$. Tho quantities $I_{k}^{(c)}$ and $F_{j}^{(c)}$ are calculated by using Eqs. (9) and (10). The program computea $I_{T}^{(c)}$ by integrating the elastic DCS over the angular region between $\theta_{c . \mathrm{m}}^{(l)}$. and $\theta_{\mathrm{c}, \mathrm{mn}}^{(2)}$, and by adding on the total inelastic crose wection when it is assumed to be nonnegligible. The fixst oummation in the expression for $M$ extends over all angles for which polarization data oxiat, the aecond oummation, over all angles for which elatic DCS data were obtained. Wo assume that the expeximental errora entering into $M$ are independent, normally distributed, and realistically estimated.

The search program require the computer to find a set of phase hift sor which $M$ has a minlmum value, beginning at a given set of phase shffs. In this way, a least-squares fit to the data is attained. Such a fit corresponds to a minimum point in the sense that a change of $\neq \Delta$ FINAL in any one of the phase ohifte gives a larger value of $M$ than the value calculated at the minimum. Here $\Delta_{\text {FINAL }}$ is the smallest increment employed when the phase shift aro varied. The resulting value of $M$ may not have the aboolute minimum magnitude obtainable, because the computer stop at the first relative minimum that it notices. Different initial sets of phase ohifts can lead to different minima, oome of which may have even lower $M$ values. 
During the search procedure, the computer varies in the same manner that it varies the phase shifts. Thus the computer ia able to modify the absolute cale of the DCS in order to improve the fit to the data. The experimental exror in $e^{(\epsilon)}$, is comprised of the uncertainties in the DCS absolute cale. Errors of this type include uncertainties in the intensity and contamination of the incident pi-meson beam and in the thickness of the liquidhydrogen target. Independent errors, such as statiotical counting uncertaintics, are attached to each DSS measurement individually and are denoted $\mathrm{F}_{\mathrm{k}}^{(\mathrm{I})}$. These independent orrors indicate the accuracy with which the various measurement are ksown with reapect to one another feffects of systematic uncertainties in the shape of the DCS are discussed in Section (III-B). The use of the varlable enable the phaso-shift analyslo to keep the independent errox In the Individual DCS measurements separate from the uncertaintie In the absolute cale, thus allowing an optimum amount of information to be obtained from the DCS data and permitting independent orrors in the expresaion for $M$. Although we will generally diaregard a in our further discussion of the program and when quoting results, it was always present in our analysis.

Owing to the influence of the mall relative error in the value of $I_{T}^{(e)}$ used, the principal effect of in our analysis was to enable the elastic DCS curve to be normalized to the total-cross-section meagurement. In performing this normalization, we usually assumed that we could neglect the Inelastic-Bcattering contribution to the total cross oection. Because the amount of inelastic cattering at $310 \mathrm{Mev}$ is apparently not appreciable, the exror Introduced by 1 ts disregard in the normalization procedure appears to be 8 mall compared with the error in the total-cross-section measurement. 
It is Illuminating to visualize the hypersurface that would be obtained if $M$ could bo plotted as a function of the phase shifta. The region around a point where $M$ has a minimum value corresponds to a depression In the hypersurface. In the phase-hift discussions to follow, we will cometimes refer to thi vioual ropresentation.

The usefulness of any possibly accoptable phase-shift fit la increased if one can ascertain the accuracy with which the experimental data determine the individual phase shifts. We employed the customary method of error calculation, which involve the error matrix. Although the details of our calculation differ somewhat from those described by Anderaon et al. 19 the general method is the ame. The square root of the diagonal elements of the error matrix give the rms orroxs in the phase shifts. Each off-diagonal element is the product of a correlation coefficient and the two related rms errora.

As a check on the results obtained from the error matrix, the rms errors In the phase shifts were also calculated by a second method. In this method, one phase hift lo changed from it value at the minimum and then held fixed while all the other phase ohifts are varled until $M$ can be decreased no infther. If we let the resulting value of $M$ be denoted $M^{\prime}{ }_{0}$ and let $M_{0}$ be the value of $M$ at the minimum point corresponding to the solution under consideration, the change required in the flxed phase shlft to give difference of unity between $M_{0}^{\prime}$ and $M_{0}$ is the rms error in that phase ohift. Errors in all the phase hifts can be calculated in this way, but at the expense of conolderably more computer time than when the error-matrix method is used. We obtained satisfactory agroement between the regults of the two methods of error determination. 


\section{B. The SPD Random Search 20}

The phase-shift investigations were begun with a random search involving S-, $P_{-}$, and D-wave phase ohifts. In order to find every minimum that might lie in the neighborhood of the true solution, the computer was anked to begin searching at a large number of random point scattered over the $M$ hyperaurface. A total of 244 random sets of phase hifts were fed into the computer. The values of all five phase ahift: $\left(S_{3,1}, P_{3,1}\right.$ ' $P_{3,3}, D_{3,3}, D_{3,5}$ ) in every et were randomly elected. The initial value of was alwaya zero. From these 244 random positions on the hypersurface, the computer searched and found 27 distinct cluster of olutions (phaseshift fite). The solutione in each cluster agree with one another to within a few tenths of a degree in every phase shift. The different clusters apparently correspond to varioue xelative minima. Each of the ten relative minima in the group with the lowest values of $M$ was detected by the computer at least five times. If one assumes that the relative minima are randomly -paced on the $M$ hypersurface and can be entered with equal ease, then the probability of having overlooked a set of phase shifts with a low $M$ value is 1ea than $1 \%$.

Since the completion of our SPD random search, both the computer program and the input data have been revised and extended. The mont important changes were the addition of a total-cross-bection measurement and the inclusion of DCS data at angles sufficiently small so that Coulombnuclear interference effects are noticeable. It is assumed that no new minima with low value of $M$ were created by the changes made. (The validity of this assumption is upported by the result of the SPDF random search to be described in Section III-D.) In general, the changes in the data 
and program produced only small alterations in the phase-shift values related to each minimum. The presence of the DCS data at small angles caused the $M$ values of several of the original minima to increase considerably. These minima correspond to sets of phase shifts that give the incorrect ign for the Coulomb-nuclear interference effects.

In all $x \in$ sult 8 to follow, wo employ the revised and extended data and program. The data used include four recoil-proton polarization measurements, ${ }^{1}$ values of the elastic DCS at 23 angles of observation, 2 and a total-cross-Bection measurement of $56.4 \pm 1.4 \mathrm{mb}$ (between the c. m. cutoff angles 14.7 and $158.0 \mathrm{deg}) .^{2}$ The polarization data are given in Table $V$ of reference 1, and the DCS data axe listed in Table III of this report. These experimental measurements are plotted in Figs. 1 and 2 . Of the 27 distinct sets of phase ahifts found in the SPD randorn search, all but three have negligible probabilities of lying in the vicinity of the true solution. We base this statement on the $x^{2}$ distribution of statistical theory. which can be applied at least approximately to our results. ${ }^{21}$ The $x^{2}$ distribution for 23 degrees of freedom is used here because we are endeavoring to fit 29 pleces of exporimental information (including $\quad=0.00 \pm 0.06$ ) with five phase shifts and the parameter $\leqslant$. The 24 solutions that were discarded on the basis of statistical theory have values of $M$ in the range 86 to 1100 , and are therefore highly improbable (the mean $M$ value expected is equal to the number of degrees of freedom). If the polarization data had not been present in the analysis, some of these improbable sets of phase shifts would have had low $M$ values and therefore could not have been discarded on the statistical basis alone.

Our three possibly acceptable solutions are presented in Table IV. The phase shifts given there are of the nuclear type. They wero acquired by subtracting the Coulomb phase shifts $\Phi_{L}^{ \pm}$. which are listed in Table $I$. 
from the total phase shifts obtained by the search program. The three oolutions in Table IV are of the Ferml type, Minami type, and Yang type. in order of increasing $M$. The connections between these sets of phase shift are not precisely the relationships one might expect because of the additional constrainte created by the polarization data. However, the features that charactexize these solutions can be noted.

Two other sets of phase shlfte are good fits to all but the DCS data at small angles. These solutions are similar to the Fermi and Yang fits in Table IV except that the signs of mont of the phase shlfte are opposite to the ofgng of the corresponding quantities in the table. Because these two solution. give degtructive Coulomb-nuclear interference in the forward direction of scattering, we can definitely oxclude them by using the DCS data at small angles (oee Fig. 2).

Figure. 1 and 2 how the manner in which the SPD Bolutione in Table IV fit the data. The DCS curves calculated from the Minami and Yang ata of phave sift are not shown; they closely resemble the Fermi plot. All three phase-shift sets give values for the total cross section that are in good agreement with the experimental measurement.

We present in Table $V$ the error matrix that is associated with our SPD Fermi colution. The phase-shift uncertainties obtained from this matrix are based on the exrors in the experimental data. In order to make the problem manageable, we have neglected the systematic uncertaintie in the shape of the DCS and have used only the independent uncertainties referred to in Section III-A. It is the Be independent errors that are given in Table III and shown in Fig. 2. We investigated the influence on the phase shifte of the systematic uncertainties just mentioned, and found the effects to be small compared with the rmo error obtained from the error matrix for the SPD Fermi solution. 
In the remainder of this section, our attention will often be concentrated on the Fermi solution given in Table IV. The reasons for disregarding the Minami and Yang sets of phaso shift will be briofly discussed in Section IV-A.

\section{Inadequate SP Fit; Ambiguity in the D-Wave Phase Shifts}

Besides our SPD analysio, we have also analyzed the data by asouming that the pion-nucleon nuclear interaction affects only the $S$ and $P$ waves. The best SP fit that we obtained is given in Table VI; the corresponding polarization and DCS curves are shown In Figs. 1 and 2. Thlo solution in of the Formi type and is obviously an inadequate fit to the experimental data. The poor fit is hown numerically in the large $M$ value of 92.5. Although the D-wave nuclear phase shift are small in our SPD Fermi set, they are definitely needed in order to obtain a atiafactory fit. 22

By comparing the SP and SPD Fermi oolutions, we observe that the Inclusion of $D$ wave in the analysis has a noticeable effect on $S_{3,1}$ and $P_{3,1}$. Each is reduced in absolute magnitude when the $D$-wave nuclear phase shifts are allowed to have values other than zero. Only the phase ohift $P_{3,3}$ is rathor insensitive to the number of partial waves included in the analysis.

When our four polarization measurements are excluded from the SFD analysis, an uncertainty appears in the $D$-wave phase shifts. This ambiguity was mentioned in Section II-D. It gives rise to two Fermi-type colutions yielding low values of $M$, instead of just the one prevlously discussed. The two Fermi phase-shift sets, obtained when only the cross-section data are utllized, are given in Table VI. (They possegs lower $M$ values than the Fermi golution in Table IV because there are fewer experimental measurements to fit.) A principal difference between these two solutions is that the 
D-wave phase shift in one set have signo reversed comparod with those in the other set. The usefulnes of the polariration data in differentiating betweon these two SPD phase-shift oolutions is demonstrated in Fig. 3.

\section{Inclusion of $F$ Waves}

Eecause of the relatively high accuracy with which the phase shifts in our SPD Fermi fit are determined, we folt it necessary to extend the analyeis to Include $F$ waves. It appeared quite posetble that the addition of small F-wave phase hifte might cause changes in the other phase shifte larger than the quoted exrors. This indeed turned out to be true. We found that the inclusion of a mall $F$-wave nucleax interaction not only alter the values of almost all the $S_{-}, P_{-}$, and $D_{\text {-wave phase }}$-wifts but atso causes their ortor to increase considerably. Also, new olutions appear that fit the data well.

With the F-wave nuclear phase shift allowed to be different from zero, another random search for solutions was conducted. New random initial values were picked for the phase ohifts related to the $S, P$, and $D$ waves. The inttial F-wave phase shifts were also chosen at random, but were restricted to the interval $0 \pm 9$ deg because we as aumed these parameter to be small. The number of random sets used was 260 , and about $t w i c e$ as many minima were found as in the SPD random search. Every molution with an $M$ value of legs than 40 was obtained at least five times. According to the $x^{2}$ distribution, now for 21 degrees of freedom, the probability is Ies than $1 \%$ that the $M$ value of the true solution is greater than 40 . As a check on the SPD random-search resulta, we made SPD fits to the data using as starting points the first five phase shifte in the various SPDE solutions. All the original SPD solutions appeared. In addition, 
only two new minima were found and these possess extremely high $M$ values. Therefore, we had apparently obtained all the oxtating SPD solution with low $M$ valued in our original randorn search.

Every SPDE solution discovered, with a value of $M$ les then 40, 1. liated in Table VII. The Fermi-I, Minami-I, and Yang-I solutions corrospond to the threo SFD fits given in Table IV. The designation "Minami-Yang" refers to the type of fit of that name mentioned in Section II-D. Many of the phase-shift values in the vartous oolution denoted "I" In Table VII are approximately connected by the ambiguity interrolationships diecuseed in the reference cited in Section II-D. Simtlarly Interrelated are the three fit denoted "II". We will dieregard solution 6 because of it excessively largo $F_{3,7}$ When SPD fite to the cross-aection data only are obtained, the SPDE Fermi-I and -II solutions reduce to the eolution of the mame names gren in Table VI and therefore appear to be manlfestations of the ambiguity In the D-wave phase shifts. The exror matrices for these two set of phase wift are presented in Tables VIII and IX.

The Fermi-II solution and the two Minami-Yang fits wexe also found In the SPD randorn search but then had improbably large $M$ value becauwe of their inability to fit the polarization data. The presence of mall F-wave phaso ohift has enabled theso three previously unacceptable solutiona to become good fits to the polariration measurements. We present in Fig. 4 the variation of the polarization with c.m. cattering angle predicted by the Arst four SPDF solutions in Table VII. The analogous curve for the wolution Minams-Yang II is intermediate between those for Fermi II and Minami-Yang I. The polarization plots for the SPDF Minami-I and Yang-1 set are essentially the same as the corresponding curvos in Fig. 1. 


\section{E. Addition of $G$ Waveo}

An attempt was made to observe the effects of $G$ wave on the SPDF analysis, agaln with the aid of the IBM-704 computer. When no reatrictions are placed on the size of the $G$-wave phase shifta, we found that our former solutions become poorly defined, and additional aet of phase ohifte appear that fit the data well. The SPDF Ferml-1 and Fermi-Il -olutions aro alterod in character coneiderably when the nuclear G-wave Interaction is allowed because the computer 18 best able to fit the data by changing some of the phase shifts in these solution by as much as 10 to $20 \mathrm{deg}$ (the $M$ values dropping to about 10 and 16, respectively). Fiven if the magnitude of the nuclear G-wave phase hifts are held to within the arbitraxy 11 mit of $0.2 \mathrm{deg}$, the uncortainties in many of the other phase shift in the two Fermi volutions increase to one and one-half to two times their former values. With the nuclear G-wave interaction allowed, we reInyestigated all the minima obtaincd in the SPDF random earch. The magnitudes of the nuclear G-wave phase shifts in a given fit wero arbitrarily restricted to be los than one-fifth the magnitude of the larger nuclear F-wave phase shift in the same fit. Fiven this constralnt did not prevent new oolutions with low $M$ values from arising. With our present data and the limited amount of available thooretical information concerning the phase shifte related to angular-momentum states of higher order, we conclude that we camot moaningfully include $G$ wave in the analysts. 


\section{DISCUSSICN OF RESULIS}

\section{A. Phase-Shift Analyois}

A comprehensive phase-shift analysis has been performed, utilizing the polarization and cross-section data now available on $\pi^{+}-p$ scattering at $310 \mathrm{Mev}$. The $\mathrm{D}$-wave phase shifts were found to be definitely needed in order to attain an adequate fit to the data. We investigated the influence on the analyais of the presence of small $F$-wave phase shifte: not only are the error in our original Fermi-type solution increased, but additional colution arise that fic the data woll. Although the introduction of a small F-wave Interaction does not greatly Improve the best obtainable fit to the data. no justification can be found for completely neglecting $F_{3,5}$ and $F_{3,7}$ Wo attempted to extend the phase-shift inquiries to include $G$ wavea but found that the available data and theory do not allow the G-wave finteraction to be oignificantly incorporated into the analyais. Evidently the region of angle over which polarization data exist is not large enough to enable us to satisfactorily define the phase shifts when $G$ waves are also assumed affected by the nuclear interaction.

Our investigations indicate that it is difficult to obtain a completely meaningful set of phase ahifte from pion-nucleon experimental data by using the partial-wave treatment alone. Further asoistance from theory may bo required before one can handle with confidence all tine angular-nomenturn etates measurably affected by the interaction. The discussions to follow will principally be limited to the results of our SFDF investigation.

Let us begin the discussion of the various phase-shift colutions by discarding all those that are of the Yang. Minami, or Minami-Yang type. A principal reason for rejecting these sets of phase shifts is that they appear 
to disagreewiththe requirements of the dispersion relations for the spin-flip amplitude of the pion-nucleon scattering in the forward direction. $13,23,24$ The Minami-type colution is also unreasonable because of its large $D_{3,3}$ and the implausible behavior of its phase shifts at low energy. 13,25

Of the phase-shift oolutions llated in Table VII, only the Fermi-I and Fermi-Il ata remain to be considered (we earlier rejected ot 6 because of 1te exceseively laxge $F_{3,7}$ ). In Table $X$, we ummaries the characteriotice of these two SPDF Fermi-type fita. The SPD Fermi set le also included for comparion. In comparing the closely related SPD Ferml and SPDF Fermi-1 colutione, we notice that only $P_{3,3}$ is essentially unaffected by the addition of the F-wave interaction fowhing to the strong dependence of this phase shift on only the total cross section). Although $F_{3,5}$ and $F_{3,7}$ in the SPDF Fermal-I colution are mall and thelr errors overlap 0 deg, the effect of their presence is considerable.

Table $X$ show the drastic increases in the phase-shift errors that occur when $F$ waves are added to the SPD Ferml solution and the SPDF Fermi-1 set in thereby obtained. Thi would seem, at first glance, to indicate that much lese information can be derived from this type of olution now that F wavea are allowed. Actually this is not true becauce many of the correlation coefficlente are large in the SPDF Fermi-I solution. Large correlation coefficient signify otrong relationships between the phase ohift, and thus information about one phase shift will, in general, give useful information about other phase whift. In any comparison of theory with the SPDF Fermi-I set, It will be important to use the entire exror matrix (Table VIII). 
To facilitate the phase-shift analysis, we neglected inelastic scattering. Additional uncertaintie in the solutions of Table $X$ exist because of this disregard of all but the elastic-scattering reaction. There is little experimental information available on inelastlc processes in $\pi^{+}-p$ ocattering at 310 Mev. However, estimates can be made of the magnitude of the total Inelastic cros gection at this energy by combining the experimental measurement of Willig 26 at $500 \mathrm{Mev}$ with theories such as those by Rodberg, 27 Franlelin, ${ }^{28}$ and Kazes. 29 The results indicate that the $n^{+}$-p total inelastic crose aection is les than $1 \mathrm{mb}$ at $310 \mathrm{Mev}$.

The inclusion in our analyois of even thi small amount of inelastic cattering can cause changes in the phase sifto. We have observed the alterations in the solutions given in Table $X$ when a total inelastic cross ection of $1 \mathrm{mb}$ is allowed. Varioue extreme assumptions were made about the manner In which this amount of inelastic scattering might be distributed among the different angular-momentum atates of the interaction. Each inelastic parameter was assumed, In turn, to have a value oufficiently less than unity 00 to account for the entire $1-\mathrm{mb}$ cross section (all the other inelastic parameters remaining at unity). Equation (7) of Willis ${ }^{26}$ was used in order to calculate these values. For each assumed set of Inelastic parameters and for each solution considered, the computer redetermined the values of the phase shifts yielding the minimum magnitude of $M$ (thi general procedure was discussed briefly in Section III-A). We conclude from the results of this investigation that, if inelastic-scattering processes could properly be taken into account, any changes in the quoted values of the phase shift would probably be well within the corresponding errors given in Table $X$. 


\section{B. Comparison of the SPDF Fermi-Type Solutions}

Let ue examine more closely the two SPDF Fermi-typo solutions, both of which are excellent fits to the data. Both sets are reasonable from the point of view that the $F$-ware phase shifts are mall compared with those related to the $\mathrm{D}$ wave. We are unwilling to discard the Fermi-II solution on the basis of lack of continuity with results of phase-shift analyses at other energies because we believe these other analyse may ouffer the same uncertainties as our SPD reeults. In the remainder of this section, comparison between the two SPDF Fermi solutions will be made in an attempt to eliminate one of these two sets of phase shifts.

Both olutions give $\operatorname{Re}\left[\mathrm{f}\left(0^{\circ}\right)\right]=-0.686 \pm 0.012 \mathrm{in}$ units of $\mathrm{n} / \mu \mathrm{c}(\mu \mathrm{de}-$ notes the $\mathrm{pl-mes}$-m rest mass) where $\operatorname{Re}\left[f\left(0^{\circ}\right)\right]$ is the real part of the forwardscattering amplitude, for $\pi^{+}-\mathrm{p}$ nuclear elastic scattering, in the c.m. system. The result, -0.686 , was calculated by inserting the nuclear phase shift of Table X into Eq. (12) of Anderson and Davidon. ${ }^{30}$ (The value computed for $\operatorname{Re}\left[f\left(0^{\circ}\right)\right]$ is almost independent of the number of partial waves as sumed to be affected by the nuclear interaction.) We obtained the error by using the erxor matrices in Tables VIII and IX. The sign of Rel $\left.f\left(0^{\circ}\right)\right]$ is determined by the absolute ign of the set of phase shift used, which in turn is determined by the aign of the Coulomb-nuclear interference contribution to the DCS. We neglect a mall correction (apparently less than $1 \%$ ) to Rel $\left.f\left(0^{\circ}\right)\right]$ arising from the disregard of possible inelastic contributions to the total cros section when the computer normalizes the experimental elastic DCS to the experimental value of the total cros section. If inelastic scattering takes place but 18 neglected in the phase-shift analysis, DCS values calculated from the resulting sets of phase shifts will be too large. Because of the close relationship 
between $\operatorname{Re}\left[f\left(0^{\circ}\right)\right]$ and the value of the DCS for nuclear scattering at $\theta_{\mathrm{c} . \mathrm{m} .}=0 \mathrm{deg}$, the disregard of inelastic scattering causes the magnitude quoted for $\operatorname{Re}\left[f\left(0^{\circ}\right)\right]$ to be olightly too great.

Our result for $\operatorname{Re}\left[f\left(0^{\circ}\right)\right]$ agrees well with values predicted by the dispexsion relations and based on other experimental data. ${ }^{31}$ The curve calculated by Spearman gives $\operatorname{Re}\left[f\left(0^{\circ}\right)\right] \approx-0.70$ for $f^{2}=0.08$, where $f^{2}$ is the renormallzed, unrationallzed, pion-nucleon coupling constant. 32 Another recent analyoid to that by Cronin, who predicts $-1.35 \times 10^{-13} \mathrm{~cm}$ at 310 Mev for the real part of the forward-ocattering amplitude in the laboratory syatem (for $f^{2}=0.08$ ). ${ }^{33}$ When tranaformed to the laboratory system, our rosult becomeg $(-1.36 \pm 0.02) \times 10^{-13} \mathrm{~cm}$, again in good agreement with the dispersion relations.

When the two SPDF Fermi-type olutions are compared with the predictions of the phase-shift formulas of Chew, Goldberger, Low, and Nambu, ${ }^{34}$ we find that Fermi $I$ is in better agreement. The P-wave phase hifte of Fermi I are more in accord with the effective-range formulas of Chew et al. than are the corresponding phase ohifts of Fermi II. The effective-range equation predict approximately $-5 \mathrm{deg}$ for $P_{3,1}$ and $127 \mathrm{deg}$ for $P_{3,3}$ at $310 \mathrm{Mev}$. We obtained these results by assuming $f^{2}=0.08$ and $\omega_{r}=2.1$. The quantity $\omega_{r}$ is the value of $\omega$ at the 3,3 resonance. where $\omega$ denotes the total energy in the c.m. system, exclusive of the nucleon rest energy, in units of $\mu c^{2}$. The effective-range formulas are expected to be valid only at low energies. Therefore the fact that the Fermi-II get disagrees more noticeably with these equations than does the Fermi-I solution la not sufficient reason by itself for discarding the former set of phase shifts. 
One often compare experimentally obtained values of $P_{3,3}$ with the effective-range theory by mean of the Chow-Low plot ${ }^{35}\left[1_{1} e_{1}\left(q^{3} \cot P_{3,3}\right) / \omega\right.$ versus $w$, where $q$ is the momentum of the pi meson in the c.m. syotem. in unit of $\mu \mathrm{c}$. The values of $\mathrm{P}_{3,3}$ in both Fermi $I$ and Fermi If give result that fall bolow the etraight line pasing through the low-energy point on this type of plot, in accord with the results of other experiments at energies near or above $300 \mathrm{Mev}$. The D-wave phase shift in the SPDF Fermi-I colution agree in ign and reaconably well in magnitude with the theoretical formulas of Chew et al. which predict $D_{3,3}=+0.3 \mathrm{deg}$ and $\mathrm{D}_{3,5}=-2.5 \mathrm{deg}$ at 310 Mov; the D-wave phase shifts in Fermi II disagree in both oign and magnitude. However. these formulas do not include the effecta of the plon-pion interaction and thus may not give accurate predictions.

The otraight-line plot ${ }^{36}$ at low energies of $s_{3,1}$ as a function of $q$ can be linearly extrapolated to $310 \mathrm{Mev}$ and compared with the values of this phase -hift In our two SPDF Ferml solutions. The extrapolated value obtained is neax -13 deg, and therefore the comparion yields the better agreement for Fermi I. Once again, this alone is not adequate evidence againot Fermi II because the linear relationship between $S_{3,1}$ and $q$ probably does not extend to onergies as high as 310 Mev.

Although both the SPDF Fermi-I and Fermi-II solutions give result: that agree with the dispersion relations predicting $\left.\mathrm{Re} f\left(0^{\circ}\right)\right)$. thes two sets of phase hifta yield contrasting results when compared with the dispersion relation for the pin-fip forward-scattering amplitude, following the method of Davidon and Goldberger. ${ }^{23,37}$ Dispersion-relation theory predicte that $y=c^{2}+C x$, where $f^{2}$ is again the pion-nucleon coupling constant, $C$ is a constant, $x$ is a given function of the energy, and $y$ depends in a stated way on the phase ahift and the energy. As shown in reference 23. Ferml- 
type phase shift that are based on SP analyses over a range of energies lower than $310 \mathrm{Mev}$ exhibit approximately the predicted $y-x$ linear behavior and extrapolate to a reasonable value of $f^{2}$. (At sufficiently low energies. we would expect the SP-type analysio to be adequate.) Strictly speaking, the function $y$ depends on the phase ohifta at all energles. Howevor, for Formitype solution and for the region of energies considered in the Davidon and Goldberger article, y depends principally on the value of the phase ahifts at the energy at which it is being ovaluated and on the bohavior of $\mathrm{P}_{3,3}$ at other energies, about which reasonable asurnption can be made when necessary. Approximate calculation using the Eermi-1 oolution give $y+0.03 \pm 0.08 ;$ when Fermi II is consldered, $y \approx+0.33 \pm 0.02$. We have included in the errors quoted only the error arising from the texm $R e\left(a_{3}\right)$ in Eq. (2.6) of reference 23. The entire error matrices (Tables VIII and $I X$ ) were used when calculating these orrors. AsBuming that the other uncertalnties in the calculation do not greatly change the general features of these results fox $y$, we find that the Fermi-I solution is in moderately good agreement with the stralght line of reference 23 (which yielde about 0.15 for $y$ at 310 Mev) but that Fermi II dis agrees. Relying on the Davidon and Goldberger analysie, then, we apparently may say that only the Fermi-I solution is admissible. 
C. Concluding Remarks

Although theory appears to favor the Fermi-I zet over the Fermi-II. further theoretical evidence and, in addition, experimental justification are desirable. Useful experimental information could probably be obtained by performing supplemental polarization measurements at sufficiently omall angles. We note in Fig. 4 that appreciably difforent values of the polarization are predicted by the two Ferml olutions at c.m. scattering angles in the vicinity of $60 \mathrm{deg}$. If a practicable method could be developed for determining the polarization of protons with energies approximating $50 \mathrm{Mev}$, one could perform recoll-proton polarization measurement that might distinguish between the two SPDF Fermi solutions. The same data might also provide experimental evidence against the SPDF Minami, Yang, and Minami - Yang solutions.

In conclusion, the success of the SPD analysis was so striking that an investigation of the ffects of $F$ waves was in order. The inclusion of F waves has given a good fit to the data, but not an appreciably better fit than in the SPD analysis. The errors in the phase shifts of the Fermi-1 type have become very much larger than they were before the $F$ waves were added, but because many of the correlation coeffictents are quite large there 16 t1ll a great deal of information contained in the SPDF analys1s. It is hoped that this work constitute a significant step in the quantitative study of plonnucleon scattering. 
The analyais deacribed herein would not have been possible without the facilities of the computer centers of the Lawrence Radiation Laboratory at both the Berkeley and Livermore ites, which are apervised by Mr. Kent $\mathrm{K}$. Curtis and Dr. Sidney Fernbach, respectively. Necessary hand calculations wore competently performed by Mesera. Stephan J. Krieger, Michael D. Scadron, and Willam F. Tivol. We are indebted to Dr. Henry P. Stapp for discusston clarifying the Coulomb-acattering problem. It is also a pleasure to acknowledge the support and counsel of Professor Emillo Segre. 
EOOTNOTES

1. J.H. Foote, O. Chamberlain, E. H. Rogers, H. M. Steiner, C. E. Wiegand, and T. Ypoilantis, Lawrence Radiation Laboratory Report UCRL-9488, Nov. 16, 1960; submitted to Phys. Rev.

2. Erneat H. Rogero, Lawrence Radiation Laboratory, private communication.

3. A more-detalled account of this work can be found in James iH. Foote,

Scattering of Positive Pions on Protons at 310 Mev: Recoil-Nucleon Polarization and Phase-shift Analysis (Theais), Lawrence Radiation Laboratory Report UCRL-9191, Sept. 1960.

4. The angle $\theta$ le measured with respect to the +2 axds, and $\phi$ is mearured In the $x-y$ plane with reepect to the $+x$ axlo, the $+y$ axd lying at $\phi=90 \mathrm{deg}$.

5. C. I. Critchfteld and D. C. Dodder, Phys. Rev. 76, 602 (1949).

6. The nonxelativiatic Coulomb phase shift of order zero in given by $\eta_{0}=\arg \Gamma(1+1 \eta)$.

7. As In the case of $\Phi_{L}$, tho phase hiftg $\sigma_{L}^{*}$ (and $\Phi_{L}$ ) are actually the differences between the rotal phase shifts (and the relativistic Coulomb phase shift $B$ ) of order $L$ and the nonrelativistic Coulomb phase shift of ordor zero.

8. Frank T. Solinitz。 FhyB. Fiov. 94, 1799 (1951).

9. H. P. Stapp. T.J. Ypsilantis, and N. Netropolis, Phys. Rev. 105, 302 (1957).

10. E'. Fermi, Fhys. Kev. 91, 947 (1953).

11. H. A. Bethe and $\because$. de Hofmann, Mesons and Fields, Vol. II (Row, Peterson and Co., Evanston, Illinoia, 1955), p. 65. 
12. Bethe and de Hoffmann, Section 32.

13. S. J. Lindenbaum and R. M. Sternheimex, Phys. Rev. 110, 1174 (1958).

14. Shigeo Minami, Progr. Theoret. Phys. (Kyoto) 11. 213 (1954);

S. Hayakawa. M. Kawaguchl, and S. Minami, Progr. Theoret. Phys. (Kyoto) 11. 332 (1954).

15. E. Clernentel and C. Villi, Suppl. Nuovo cimento 3, 474 (1956);

E. Clementel and C. Villi, Nuovo clmerito 5, 1343 (1957).

16. A preliminary discussion of our phase-ghift analysis and its results can be found in J. H. Foote, O. Chamberlain, H.H. Rogero, H. M. Steiner. C. Wiegand, and T. Ypsilantis, Phys. Rev. Lettera 4, 30 (1950). The numbers presented there differ somewhat from the corresponding quantities quoted in this report becauso of subsequent revision and extension of the data.

17. E. Fermi, N. Metropolis, and I. F. Alei, Phy. Rev. 95, 1581 (1954).

18. Wo wish to thank Mr. Kent K. Curtis of the Mathematical and Computing Section of the Theoretical Group Lawroncc Radiation Laboratory. for ouggesting this procedure. Appreciation is also duo Mr. Fdwin M. Towster of the same department for other useful programming ideas.

19. H. L. Anderson, W. C. Davidon, M. Glicksman, and U. E. Kruse, Phys. Rev. 100, 279 (1955).

20. The notation SPD will refer to our analysis involving $S_{-}, F_{-}$, and $D-$ wave nuclear phase shifts only. We whll also use the abbreviations SP and SPDF, which are variations of this notation.

21. P. Cziffra and M. J. Moravecik, A Practical Guide to the Method of Least Squares, Lawrence Radiation laboratory Report UCRL,-8523, Oct. 1958, p. 17; Frank Solmitz, Notes on the Least-Squares and Maximum-Likelihood Methods, Institute for Nuclear Studies, The University of Chicago (unpublished report). 
22. The D-wave phase ahifts agree with those found by E. L. Grigor'er and N. A. Mitin at $307 \mathrm{Mev;}$ nee Soviet Physics JFTP 37(10). 295 (1960).

23. W. C. Davidon and M. L. Goldberger, Phys. Rev. 104, 1119 (1956).

24. W. Gilbert and G. R. Screaton, Phys. Rev. 104, 1758 (1956).

25. Bethe and de Hoffmann, op. cit. p. 75.

26. Willam J. Willis, Fhys. Rev. 116, 753 (1959).

27. Loonard S. Rodberg, Phys. Rev. Letters 3, 58 (1959).

28. Jerrold Franklin, Phys. Rev. 105. 1101 (1957).

29. Emil Kare. Phys. Rev. 107. 1131 (1957).

30. H. L. Ander on and W. C. Davidon, Nuovo cimento 5, 1238 (1957).

31. We acknowledge informative dlocussions with Dr. H. P. Noyes. Lawrence Radiation Laboratory, concerning the dispersion relations.

32. T. D. Spearman, Nuovo cimento 15, 147 (1960).

33. James W. Cronin, Phys. Rev. 118, 824 (1960).

34. G. F. Chew, M. L. Goldberger, F. E. Low, and Y. Nambu, Phys. Rov. 106. 1337 (1957).

35. G. F. Chow and F: E. Low, Phys. Rev. 101, 1570 (1956).

36. Jay Orear, Phys. Rev. 96,176 (1954) and Nuovo cimento 4. 856 (1956).

37. Wo thank Professor J. Aahkin of Carnegie Institute of Technology, Pitteburgh. Pa. . for suggesting the use of the pin-flip dispersion relations as a possible means of discriminating between the two SPDF Fermi solutions. 
Table 1. Nonrelativiatic Coulomb phase hifts, first-order relativistic corrections, and corrocted Coulomb phase shifte (all in degrees) at an incident pion laboratory kinmic eneryy of 310 Mov. The oigns given here apply to $\pi^{+}-p$ scaitering.

\begin{tabular}{llllll}
$L$ & $\Phi_{L}$ & $\Delta \Phi_{L}^{+}$ & $\Delta \Phi_{L}$ & $\Phi_{L}^{+}$ & $\Phi_{L}$ \\
\hline 0 & 0.00 & 0.09 & - & 0.09 & - \\
1 & 0.44 & 0.09 & -0.17 & 0.53 & 0.27 \\
2 & 0.66 & 0.06 & -0.09 & 0.72 & 0.57 \\
3 & 0.81 & 0.04 & -0.06 & 0.85 & 0.75 \\
4 & 0.92 & 0.03 & -0.04 & 0.95 & 0.88
\end{tabular}

Table II. Phate-nhift notation for $\pi^{+}-$p acattering

\begin{tabular}{ccc}
\hline$L$ & $J$ & $\begin{array}{c}\text { Phase-shift } \\
\text { symbol }\end{array}$ \\
\hline 0 & $1 / 2$ & $S_{3,1}$ \\
1 & $1 / 2$ & $P_{3,1}$ \\
1 & $3 / 2$ & $P_{3,3}$ \\
2 & $3 / 2$ & $D_{3,3}$ \\
2 & $5 / 2$ & $D_{3,5}$ \\
3 & $5 / 2$ & $F_{3,5}$ \\
3 & $7 / 2$ & $F_{3,7}$ \\
\hline
\end{tabular}


Table III. Experimental DCS meacurement: (in the c.m. oystemi) used in the phase-shift analyols. ${ }^{2}$ The errors given are atandard deviations and are independent. Not included to an rme exror of approximately $\$ 6 \%$ in the absolute DCS scale.

$\begin{array}{lc}\text { C.m. } \\ \begin{array}{c}\text { cattering angle } \\ \text { (deg) }\end{array} & 1\left(0_{\text {c. ma. }}^{\prime}\right. \\ \text { (mb/oterad) }\end{array}$

14.0

$18.71 \pm 0.60$

19.6

$16.05 \pm 0.46$

25.2

$13.82 \pm 0.31$

30.6

$12.99 \pm 0.25$

34.6

$12.28 \pm 0.27$

36.2

$11.65 \pm 0.27$

44.0

$9.82 \pm 0.15$

51.8

$8.59 \pm 0.26$

56.8

$7.54 \pm 0.28$

60.0

$6.58 \pm 0.22$

69.6

$4.73 \pm 0.10$

75.3

$3.62 \pm 0.09$

81.6

$2.77 \pm 0.08$

97.8

$1.66 \pm 0.07$

105.0

$1.51 \neq 0.06$

108.1

$1.62 \pm 0.07$

120.9

$2.08 \pm 0.08$

135.2

$2.93 \pm 0.14$ 
Table III. Continued

\begin{tabular}{cl}
\hline $\begin{array}{c}\text { C.m. } \\
\text { scattering angle } \\
(\mathrm{deg})\end{array}$ & $\begin{array}{c}I\left(\theta_{\mathrm{c} . \mathrm{m.}}\right) \\
(\mathrm{mb} / \text { oterad) }\end{array}$ \\
\hline 140.6 & $3.36 \pm 0.12$ \\
144.7 & $3.76 \pm 0.15$ \\
152.2 & $4.10 \pm 0.21$ \\
156.4 & $4.51 \pm 0.17$ \\
165.0 & $4.88 \pm 0.12$ \\
\hline
\end{tabular}


Table IV. Solution found in the SPD random nearch that best fit the experimental data. The mean $M$ value expected is 23.

Type of solution

$\mathbf{M}$

Nuclear phase ehift(deg)

$\begin{array}{lllll}S_{3,1} & P_{3,1} & P_{3,3} & D_{3,3} & D_{3,5}\end{array}$

\begin{tabular}{|c|c|c|c|c|c|c|}
\hline Forml & 15.8 & -18.5 & -4.7 & 134.8 & 1.9 & -4.0 \\
\hline Minami & 32.0 & -7.1 & -22.3 & -1.9 & 135.6 & 0.8 \\
\hline Yang & 37.7 & -23.2 & 126.2 & 159.0 & 7.5 & -4.6 \\
\hline
\end{tabular}

Tablo V. Error matrix for the SPD Fermi solution. The matrix olemente are $\ln (\operatorname{deg})^{2}$.

\begin{tabular}{|c|c|c|c|c|c|}
\hline$s_{3,1}$ & 0.41 & 0.26 & 0.17 & 0.11 & -0.20 \\
\hline$P_{3,1}$ & & 0.32 & 0.05 & 0.11 & -0.18 \\
\hline$p_{3,3}$ & & & 0.42 & -0.01 & 0.05 \\
\hline$D_{3,3}$ & & & & 0.13 & -0.10 \\
\hline$D_{3,5}$ & & & & & 0.19 \\
\hline
\end{tabular}


Table VI. The "SP Ferml" solution is our best SP fit to the experimental data. "Ferml I" and "Fermi II" are the two SPD Fermi solution. with low $M$ values that are obtained when the computer is required to fit only the cross-section data (these solutions exhibit the ambiguity in the $D$-wave phase shifts).

\begin{tabular}{|c|c|c|c|c|c|c|c|}
\hline \multirow{2}{*}{$\begin{array}{l}\text { Type of } \\
\text { solution }\end{array}$} & \multirow{2}{*}{$\begin{array}{l}\text { Mean } M \\
\text { expected }\end{array}$} & \multirow{2}{*}{$\begin{array}{c}\text { Computed } \\
\mathbf{M}\end{array}$} & \multicolumn{5}{|c|}{ Nuclear phase shift (deg) } \\
\hline & & & $s_{3,1}$ & $P_{3,1}$ & $P_{3,3}$ & $D_{3,3}$ & $\mathbf{D}_{3}$ \\
\hline SP Ferml & 25 & 92.5 & -22.3 & -8.1 & 136.1 & 0 & 0 \\
\hline Ferma I & 19 & 13.9 & -16.8 & -4.0 & 134.8 & 3.3 & -5.4 \\
\hline Ferml u & 19 & 14.1 & -24.0 & -8.8 & 137.3 & -3.5 & 2.4 \\
\hline
\end{tabular}


Table VII. Solutions found in the SPDF random search that possess values of $M$ less than 40 . $T$ he mean $M$ value expected is 21 .

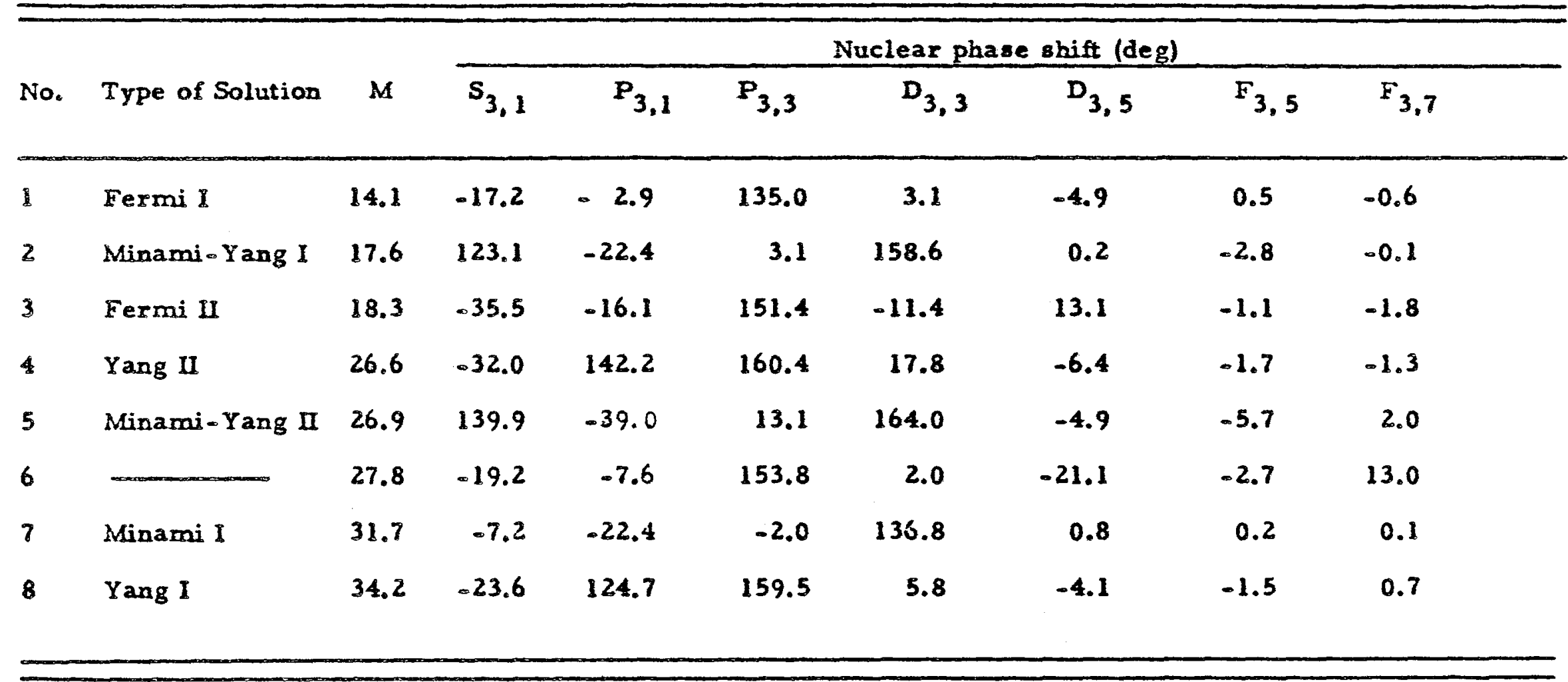


Table VIII. Error matrix for the SPDF Formi-I solution. The matrix elements are in $(\text { deg })^{2}$.

\begin{tabular}{|c|c|c|c|c|c|c|c|}
\hline & $s_{3,1}$ & $P_{3,1}$ & $P_{3,3}$ & $D_{3,3}$ & $D_{3,5}$ & $F_{3,5}$ & $F_{3,7}$ \\
\hline$s_{3,1}$ & 6.93 & 10.38 & -0.08 & 6.65 & -5.56 & 1.27 & -3.61 \\
\hline$P_{3,1}$ & & 16.14 & -0.36 & 10.34 & -8.54 & 1.96 & -5.66 \\
\hline$P_{3,3}$ & & & 0.42 & -0.28 & 0.27 & -0.05 & 0.16 \\
\hline$D_{3,3}$ & & & & 6.76 & -5.51 & 1.28 & -3.67 \\
\hline $\mathrm{D}_{3,5}$ & & & & & 4.61 & -1.04 & 3.00 \\
\hline$F_{3,5}$ & & & & & & 0.31 & -0.70 \\
\hline$F_{3,7}$ & & & & & & & 2.03 \\
\hline
\end{tabular}


Table 1X. Exror matrlx for the SPDF Fermi-II solution. The matrix loments are in (deg) $)^{2}$.

\begin{tabular}{|c|c|c|c|c|c|c|c|}
\hline & $s_{3,1}$ & $P_{3,1}$ & $P_{3,3}$ & $\mathrm{D}_{3,3}$ & $D_{3,5}$ & $F_{3,5}$ & $F_{3,7}$ \\
\hline$s_{3,1}$ & 0.50 & -0.11 & 0.30 & -0.08 & 0.08 & -0.08 & 0.13 \\
\hline$P_{3,1}$ & & 0.43 & -0.37 & 0.24 & -0.30 & 0.13 & -0.11 \\
\hline$P_{3,3}$ & & & 0.70 & -0.25 & 0.26 & -0.13 & 0.12 \\
\hline $\mathrm{D}_{3,3}$ & & & & 0.22 & -0.22 & 0.08 & -0.08 \\
\hline$D_{3,5}$ & & & & & 0.29 & -0.11 & 0.11 \\
\hline$r_{3,5}$ & & & & & & 0.08 & -0.06 \\
\hline$F_{3,7}$ & & & & & & & 0.09 \\
\hline
\end{tabular}


Table $X$. Phase shifte for oolutions of the Fermi type arising in the SPD and SPDF analyses of $\pi^{+}-p$ ucattering data at 310 Mev. The unite are degrees. The orrors are standard deviations and are the aquare roots of tho diagonal elemente of the error matrices presented in Tables V. VIII, and IX.

\begin{tabular}{|c|c|c|c|}
\hline \multirow{3}{*}{$\begin{array}{l}\text { Nuclear } \\
\text { phase } \\
\text { ahdft }\end{array}$} & \multicolumn{3}{|c|}{ Solution } \\
\hline & SPD & SPDF Fermi I & SPDF Fermí \\
\hline & $(M=15.8$ & 14.1 & 18.31 \\
\hline$s_{3,1}$ & $-18.5 \pm 0.6$ & $-17.2 \pm 2.6$ & $-35.5 \pm 0.7$ \\
\hline$P_{3,1}$ & $-4.7 \pm 0.6$ & $-2.9 \pm 4.0$ & $-16.1 \div 0.7$ \\
\hline$P_{3,3}$ & $134.8 \pm 0.6$ & $135.0 \pm 0.6$ & $151.4 \pm 0.8$ \\
\hline$D_{3,3}$ & $1.9 \pm 0.4$ & $3.1 \pm 2.6$ & $-11.4 \pm 0.5$ \\
\hline$D_{3,5}$ & $-4.0 \pm 0.4$ & $-4.9 \pm 2.1$ & $13.1 \pm 0.5$ \\
\hline$F_{3,5}$ & & $0.5 \pm 0.6$ & $-1.1 \pm 0.3$ \\
\hline$F_{3,7}$ & - & $-0.6 \pm 1.4$ & $-1.8 \pm 0.3$ \\
\hline
\end{tabular}




\section{FIGURE LEGENDS}

Fig. 1. Experimental recoil-proton polarization measuroment given in Table $V$ of reference 1 . The solld curves represent the fits to the data predicted by the SPD colutions in Table IV of this work. The SP fit, which io discussed in Section III-C, is indicated by the dashed curve.

Fig. 2. The experimental c.m. DCS meauuremente given in Table III have been multiplied by $1+$ to normalize them to the total cros section. The value of used $(-0.018)$ is that giving the minimum magnitude of $M$ for both the SPD and SP Fermi-type solutions. Independent error only are hown. The solid curve, which represents the Fermi SPD olution, fits the data well. The dot-dash curve at mall angles show the behavior of the SPD Fermi and Yang colutions that posses phase-shift igno opposite to those given in Table IV. The curve with ohort dashes, shown only at large angles, is the Ferrni SP fit discussed in Section III-C. It is given only where it deviates oufficiently from the SPD fit to be easily drawn.

Fig. 3. Variation of polarization with angle predicted by the two SPD Fermi olution with low $M$ value that are obtained when the computer fits only the cros-section data. These solutions exhibit the ambiguity in the D-wave phase shifts. The values of the phase ahifts for these fits are given in Table VI. When the four polarlzation measurements (Bhown above) are included in the SPD analysis, the Fermi-I curve can be easily altered to fit the polarization data but the Fermi-II curve cannot.

Fig. 4. Variation of polarization with c.m. scattering angle predicted by the firgt four SPDF solutions in Table VII. For reasons of clarity, the large-angle behavior of two of the curves is not shown. All curves satisfactorily fit the three negative polarization measurements. 


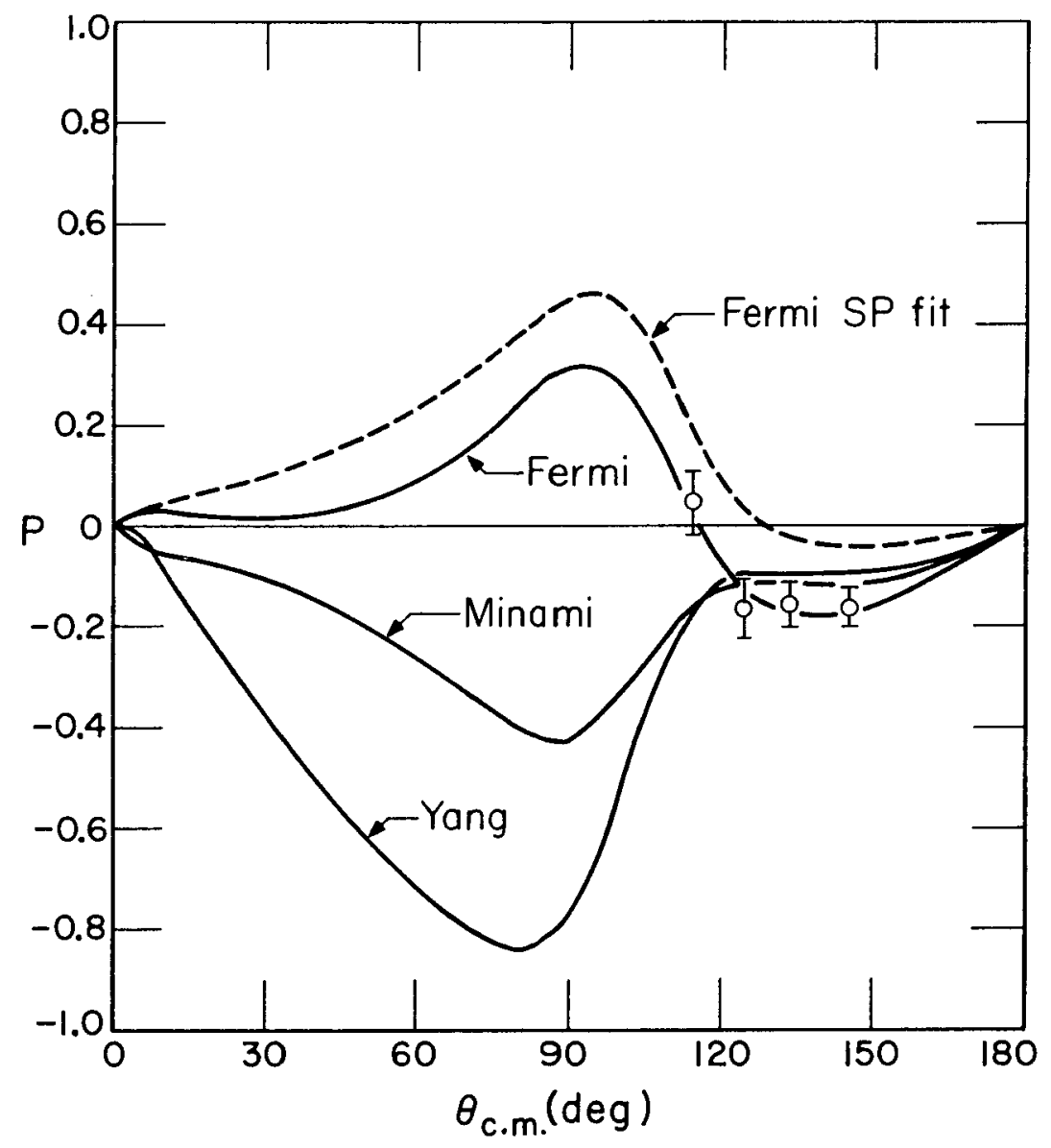

$M U-20552$

Fig. 1。 



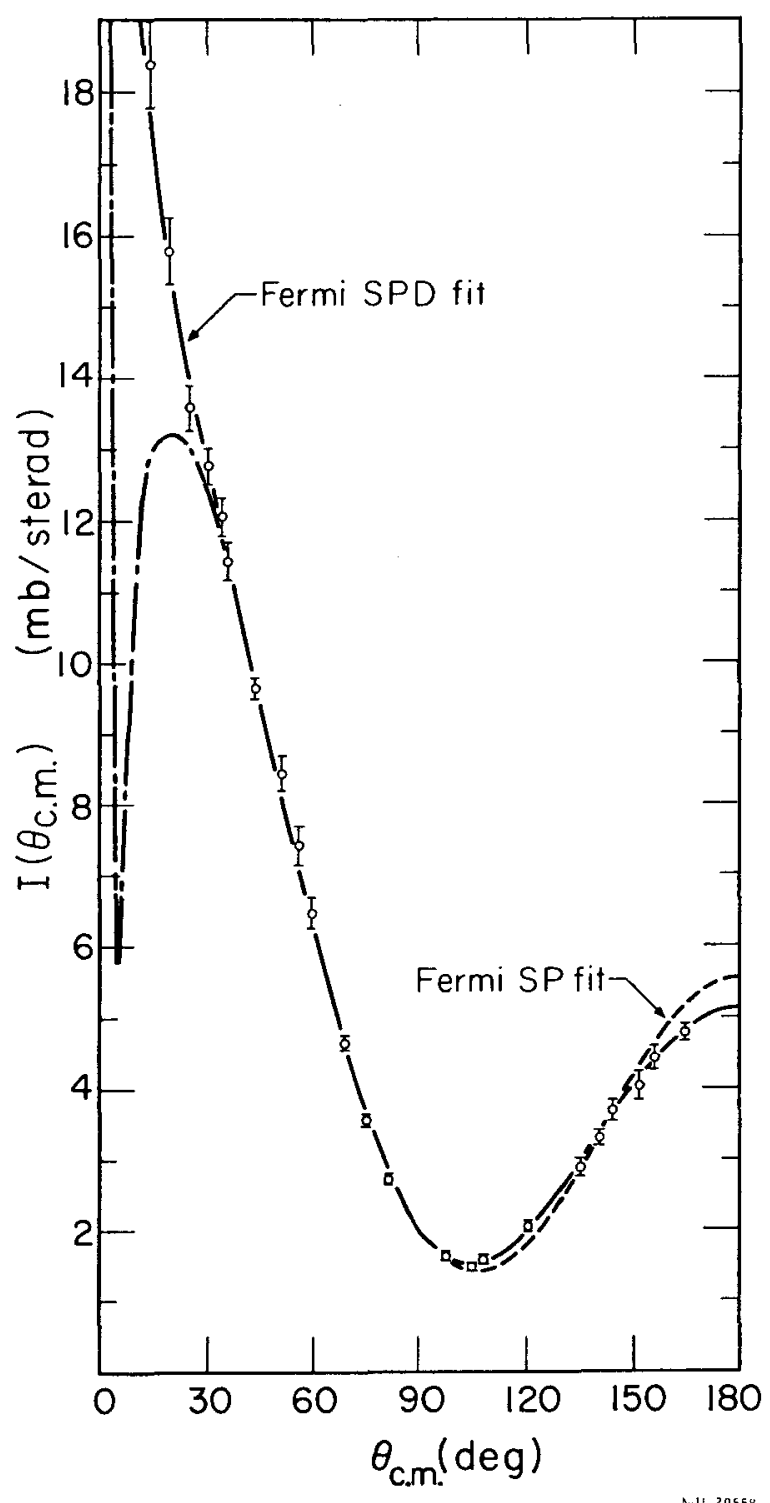

Fig. 2 . 



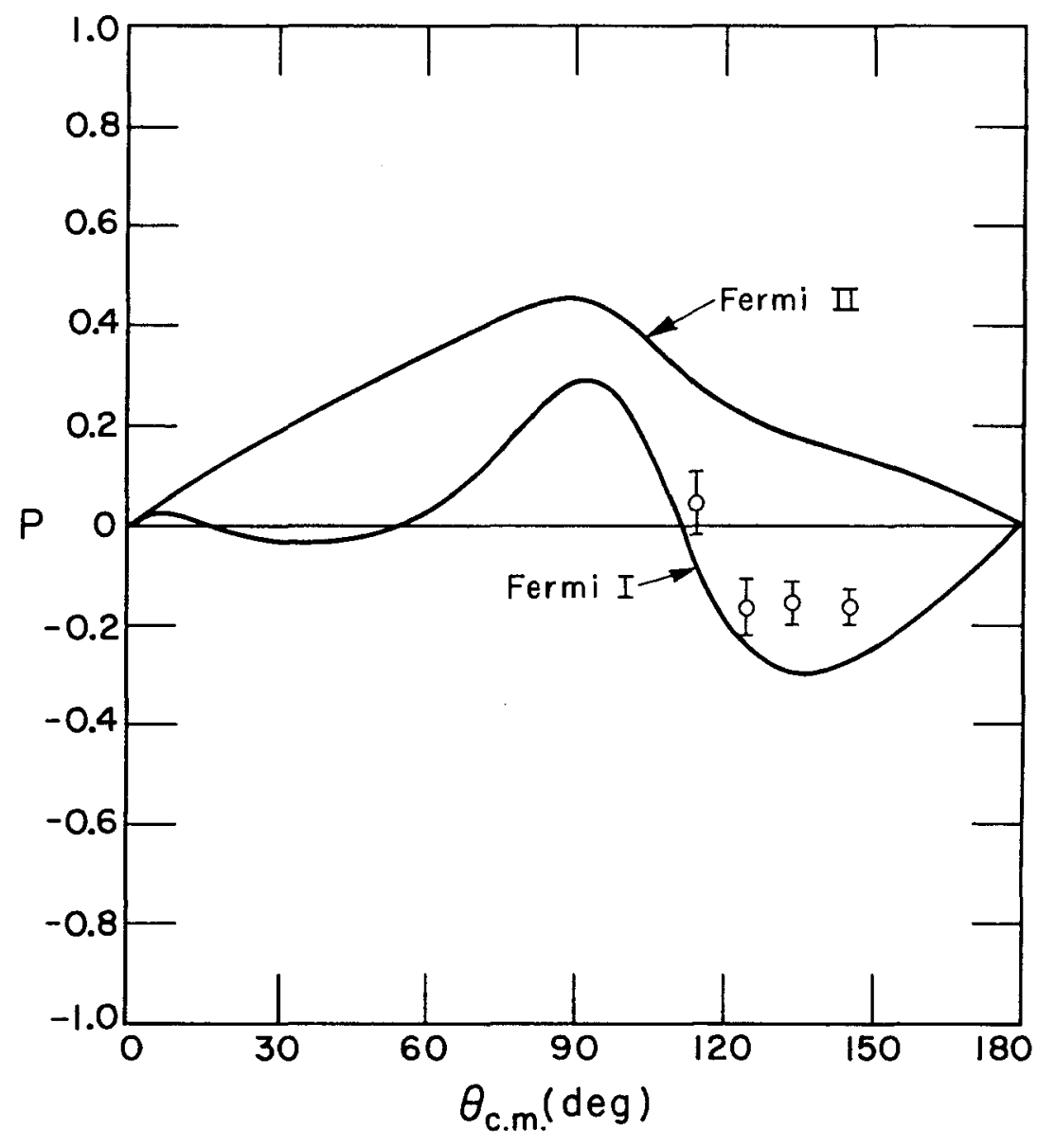

$M U-20554$

Fig. 3. 



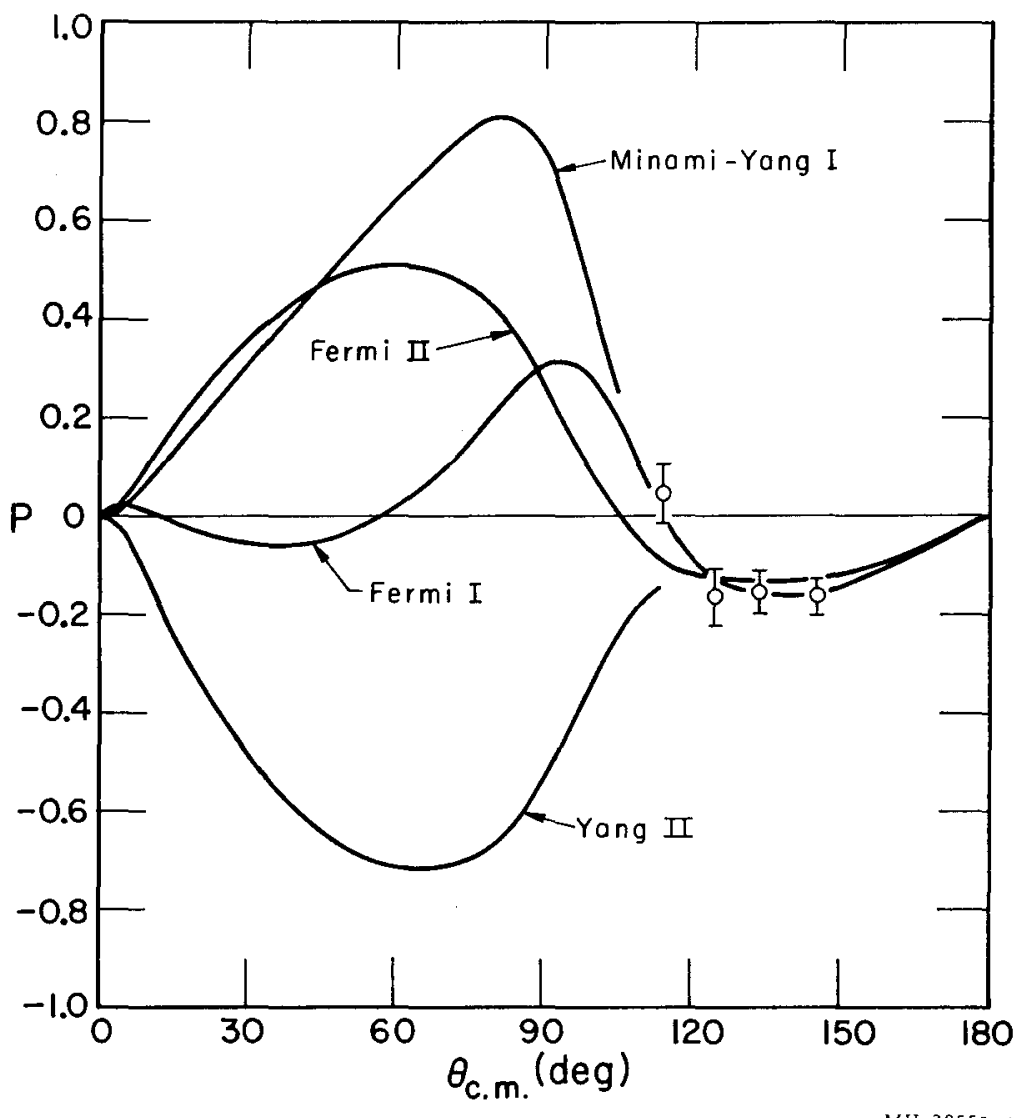

Fig. 4. 

This report was prepared as an account of Government sponsored work. Neither the United States, nor the Commission, nor any person acting on behalf of the Commission:

A. Makes any warranty or representation, expressed or implied, with respect to the accuracy, completeness, or usefulness of the information contained in this report, or that the use of any information, apparatus, method, or process disclosed in this report may not infringe privately owned rights; or

B. Assumes any liabilities with respect to the use of, or for damages resulting from the use of any information, apparatus, method, or process disclosed in this report.

As used in the above, "person acting on behalf of the Commission" includes any employee or contractor of the Commission, or employee of such contractor, to the extent that such employee or contractor of the Commission, or employee of such contractor prepares, disseminates, or provides access to, any information pursuant to his employment or contract with the Commission, or his employment with such contractor. 
